\title{
Rare Presentation of Pilar Cyst of the Thumb
}

\author{
Kavish Maheshwari*, Sandip Hindocha, Ali Yousif
}

Department of Plastic Surgery, Bedford Hospital NHS Trust, South Wing, MK429DJ, UK

*Corresponding Author:

Kavish Maheshwari, MRCS, Mch

(Plast),

Department of Plastic Surgery, Bedford Hospital NHS Trust, South Wing, MK429DJ, UK.

Email: dr.kavish@gmail.com

Received: January 21, 2018

Revised: February 9, 2019

Accepted: February 18, 2019
ABSTRACT

Pilar cysts are common cysts on the scalp and hair bearing area of the body. We found one such cyst on the dorsum of the thumb. There have been previous reports of them in the finger tips as a very rare occurrence. The site of this lesion supports the theory of a possible origin from the nail matrix. These lesions, even when found at unusual sites should have pilar cyst as a differential diagnosis. They must always be excised and subjected to careful histopathology to rule out proliferating trichilemmal cysts, which carry a rare risk of malignancy.

\section{KEYWORDS}

Pilar cyst; Trichilemmal cyst; Benign hand cyst

Please cite this paper as:

Maheshwari K, Hindocha S, Yousif A. Rare Presentation of Pilar Cyst of the Thumb. World J Plast Surg 2019;8(2):259-261. doi: 10.29252/ wips.8.2.259.

\section{INTRODUCTION}

Cystic lesions of the skin are one of the most common lumps involving the skin and adnexal tissues. ${ }^{1}$ The most common term used is sebaceous cyst, which however now is acknowledged as two types of cysts including epidermal cysts, that arise from the epidermis and pilar cysts that arise from the piliary apparatus. Approximately 20\% of epithelial cysts are trichilemmal cyst and $80 \%$ are epidermal. ${ }^{2}$ Pilar cysts were termed by Pinkus as trichilemmal cysts, when he identified the follicular isthmus of the external root sheath of the hair follicle to be giving rise to these., ${ }^{3,4}$ These lesions arise in areas of high follicular density with occasionally being found at back, vulva, nose, mons pubis, buttock, wrist, chest, elbow, or eyes. ${ }^{5-8} \mathrm{We}$ present a case of pilar cyst in an extremely rare location.

\section{CASE REPORT}

A 79-year old lady presented with a lump in her left thumb, which had been present for a few months. On examination, it was a small 1 by $1 \mathrm{~cm}$ lump proximal to the base of the nail, over the dorsal aspect of the distal phalanx of the left thumb. It had been slowly growing with no history of discharge or infection (Figure 1). She was referred as a possible differential diagnosis of mucoid cyst, epidermoid cysts or squamous cell carcinoma. An X-ray of the involved finger was also done, which did not show any bony spur (Figure 2). We did an excision of the lesion under local anesthesia. The procedure was uneventful and the lesion could 


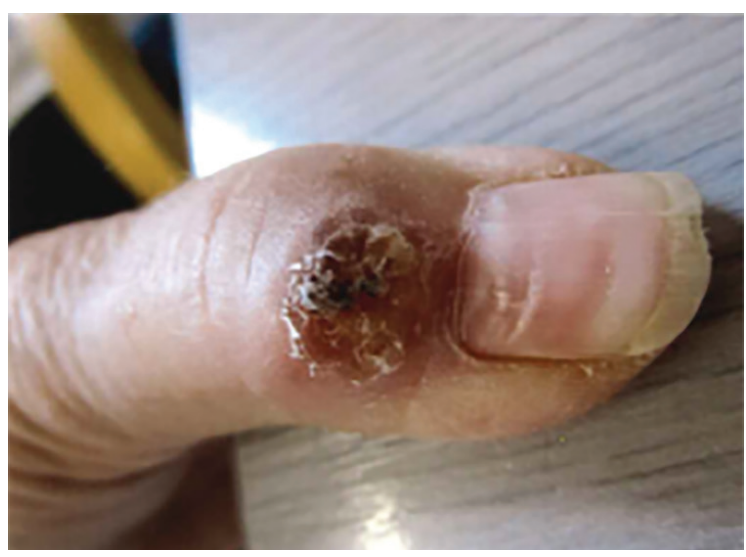

Fig. 1: Appearance of lesion at presentation to the clinic.

be easily dissected from the surrounding tissue. The histopathology evaluation was suggestive of a cystic lesion lined by squamous epithelium and suggestive of an inflamed pilar cyst. There was no recurrence at her 3 month follow up and the operative site had healed well.

\section{DISCUSSION}

Pilar cysts are usually a solitary intradermal or sub cutaneous lesion. They are clinically indistinguishable from epidermal cysts, but are far less common than them. They are most commonly found on the scalp. ${ }^{3,9}$ In contrast to epidermal cysts, they do not have a punctum. They can be easily enucleated. On gross examination, they are smooth walled cysts which on sectioning show cream white semi solid cheesy contents. They are lined by stratified squamous epithelium. Their keratinization is abrupt with no intervening granular layer and they contain homogeneous eosinophilic materials unlike the lamellated keratin flakes in an epidermal cyst. ${ }^{3}$

A previously held notion proposed that they could not arise in the palms and soles, ${ }^{9}$ however, it is no longer found to be true. There have been three reported cases of pilar cysts on the hand previously, ${ }^{10-13}$ but all of these lesions were present in the finger tips. They all arose in the non-hair bearing skin of the hand and in finger tips only. Our patient had it in the thumb and on the dorsum of the thumb, proximal to the nail bed. One of these case reports suggests the origin of this cyst as probably the nail matrix whose keratinization is trichilemmal. ${ }^{12}$ The location of this patient's cyst seems to support this theory and offers an explanation to the origin of the cyst in a non-hair bearing part of the body.

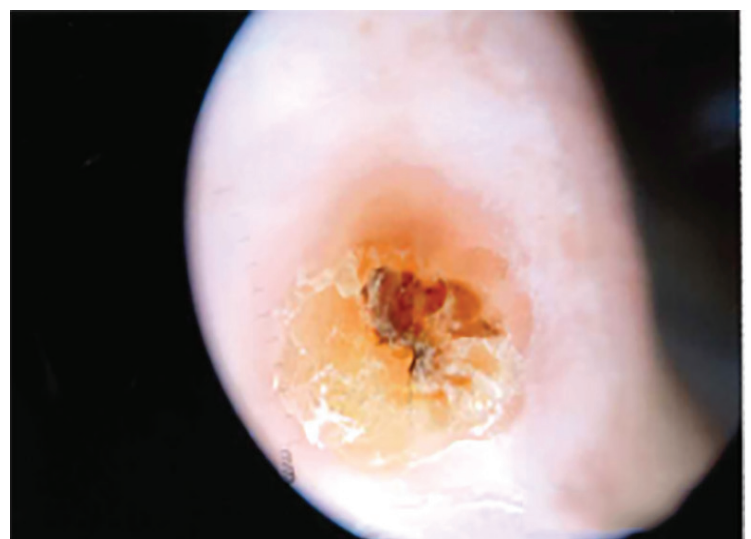

Fig. 2: View through Dermatoscope.

Apart from the hand, they are also reported to arise in the anal region, ${ }^{13}$ penile region ${ }^{14}$ and around the eyes. ${ }^{7,8}$ The pathogenesis of these cysts in the perianal region was thought to develop on the wall of a previous hair follicle cyst as a result of trauma or inflammation. There is a poorly established suspected causal relationship with infection by the human papilloma virus. ${ }^{13}$ Interestingly, the trichilemmal cyst reported on the penis region occurred after a hypospadias repair. They hypothesized that the distal hypospadias repair had triggered squamous metaplasia with keratinization, which lead to the development of a trichilemmal cyst in a nonhair-bearing area of the body. ${ }^{14}$ The trichilemmal cyst identified in the eyelid, was also found at a site of previous chalazion excision. ${ }^{8}$ Thus, trauma seems to be the most likely cause of such cysts in unusual places.

These cysts may grow more extensively and form proliferating trichilemmal tumors, also called proliferating trichilemmal cysts, which are benign but may grow aggressively at the cyst site. , $, 3,8,15$ Very rarely, trichilemmal cysts and proliferating trichilemmal tumors can undergo malignant transformation. ${ }^{2,16}$ The important differential diagnoses for a pilar cyst are proliferating trichilemmal tumors, proliferating epidermoid or infundibular cyst and trichilemmal carcinoma $^{3}$ and thus warrant a removal always. We were referred this patient as a possible squamous cell carcinoma and we operated with a differential diagnosis of a mucoid cyst. Pilar cysts can arise in unusual locations of the body, even where they are devoid of any hair follicles. They are mostly preceded by some trauma, which may not always be documented. The need to rule out the possibility of proliferating pilar 
tumors is essential, since they have a rare risk of malignant transformation.

\section{CONFLICT OF INTEREST}

The authors declare no conflict of interest.

\section{REFERENCES}

1 Rao K, Jagade M, Kale V, Kumar D, Hekare A. An Economical Method of Auricular Splinting in Management of Auricular Pseudocyst. World J Plast Surg 2018;7:220-5.

2 Chandrasekaran V, Parkash S, Raghuveer CV. Epidermal cysts - a clinicopathological and biochemical study. Postgrad Med J 1980;56:823-7. doi: 10.1136/pgmj.56.662.823.

3 Ramaswamy AS, Manjunatha HK, Sunilkumar B, Arunkumar SP. Morphological spectrum of pilar cysts. $N$ Am J Med Sci 2013;5:124-8. doi: 10.4103/1947-2714.107532.

4 Pinkus H. "Sebaceous cysts" are trichilemmal cysts. Arch Dermatol 1969;99:544-55.doi: 10.1001/archderm.99.5.544.

5 Kim UG, Kook DB, Kim TH, Kim CH. Trichilemmal Carcinoma from Proliferating Trichilemmal Cyst on the Posterior Neck. Arch Craniofac Surg 2017;18:50-3. doi: 10.7181/acfs.2017.18.1.50.

6 Markal N, Kurtay A, Velidedeoglu H, Hucumenoglu S. Malignant transformation of a giant proliferating trichilemmal tumor of the scalp: patient report and literature review. Ann Plast Surg 1998;41:314-6.doi: 10.1097/00000637-199809000-00017.

7 Kadri R, Parameshwar D, Ilanthodi S, Hegde S. Trichilemmal cyst of the bulbar conjunctiva: a rare presentation. Middle East Afr J Ophthalmol 2013;20:366-8. doi: 10.4103/0974-9233.119999.

8 Meena M, Mittal R, Saha D. Trichilemmal cyst of the eyelid: masquerading as recurrent chalazion. Case Rep Ophthalmol Med 2012;2012:261414. doi: 10.1155/2012/261414.

9 Leppard BJ, Sanderson KV. The natural history of trichilemmal cysts. Br J Dermatol 1976;94:379-90.doi: 10.1111/j.1365-2133.1976. tb06115.x.

10 Melikoglu C, Eren F, Keklik B, Aslan C, Sutcu M, Zeynep Tarini E. Trichilemmal cyst of the third fingertip: a case report. Hand Surg 2014;19:131-3. doi: 10.1142/ S0218810414720113.

11 Ikegami T, Kameyama M, Orikasa H, Yamazaki K. Trichilemmal cyst in the pulp of the index finger: a case report. Hand Surg 2003;8:253-5.doi: 10.1142/s0218810403001765.

12 El Hassani Y, Beaulieu JY, Tschanz E, Marcheix PS. [Proliferating trichilemmal tumor of the pulp of a finger: case report and review of the literature]. Chir Main 2013;32:117-9. doi: 10.1016/j.main.2013.02.002.

13 D'Avila DG, Kanno DT, de Castilho da Silva D, Pastro VR, Novelli PCS, de Paula Freitas BZ, Martinez CAR. A proliferating trichilemmal cyst in the perianal region: A case report. Int J Surg Case Rep 2018;53:1758. doi: 10.1016/j.jisscr.2018.09.049.

14 Madan S, Joshi R. Trichilemmal cyst of the penis in a paediatric patient. Sultan Qaboos Univ Med J 2015;15:e129-32.

15 Mehrabani D, Tabei S, Heydari S, Shamsina S, Shokrpour N, Amini M, Masoumi S, Julaee H, Farahmand M, Manafi A. Cancer occurrence in Fars province, southern Iran. Iran Red Crescent Med J 2008;10:314-22.

16 Lee SJ, Choi KH, Han JH, Kim YD. Malignant proliferating trichilemmal tumor of the lower eyelid. Ophthalmic Plast Reconstr Surg 2005;21:349-52.doi: 01.iop.0000167787.91245.f6. 